\section{DETERMINANTS OF TOBACCO USE IN A SELECTED URBAN AREA OF BANGLADESH}

Gias Uddin', Md. Mizanur Rahman² Syed Md. Akram Hussain ${ }^{3}$

\section{Abstract:}

Tobacco consumption is harmful to health, and is one of the main causes of death in worldwide. It is evident that the prevalence of tobacco consumption is raising in most of low and middle income countries. Considering this, a cross sectional study was conducted in a selected urban area of southern Bangladesh with a view to assessing the prevalence of tobacco consumption and factors affecting the use of tobacco use. Multistage cluster sampling technique was adopted to select the urban ward and the respondents were selected systematically. A total of 399 respondents were interviewed face to face using a semi-structured interview schedule. Analysis shows that $30 \%$ of the population of aged 18 years above were currently using tobacco of any form. The mean age of starting tobacco use was 18.8 years. The most frequent form of tobacco use was smoking cigarette followed by Zarda with betal quid. Multivariate analysis revealed that illiterate respondents were 3.3 times more tobacco users than their educated counterparts. It was also higher among the Muslims (OR=4.979; 95\% CI=1.255-19.754). Tobacco use was also high among the labouerer $(\mathrm{OR}=8.541 ; 95 \% \mathrm{CI}=2.422-30.120)$ and businessmen (OR=7.727, 95\% CI=2.501-23.875). However, no statistically significant association was found between current tobacco use and age, sex, housing condition and knowledge on tobacco use ( $>>0.05)$. The finding of this study suggests that as tobacco use is more prevalent among the poor and illiterate segment of the population, strong implementation of anti-tobacco legislation is warranted.

\section{Introduction:}

Tobacco use appeared to be an important predictor of premature death and ill-health in the developing world. It is an important risk factor-cancers, respiratory diseases and cardiovascular diseases. ${ }^{1}$ World Health Organization (WHO) reported that each year about 4 million deaths are attributable to tobacco use and among them $70 \%$ of those deaths occur in developing countries. It is also expected that the number of tobacco-related deaths will increase 8.4 million by $2020^{2}$. Guindon and Boisclair (2003) analyzed that currently, almost 1.3 billion adult uses tobacco. Analysis predicted that if the

1. Junior Health Education Officer, Meherpur Sadar Hospital, Meherpur.

2. Associate Professor and Head, Department of Biostatistics, NIPSOM, Dhaka.

3. Professor and Chairman, Department of Oncology, Bangabandhu Sheikh Mujib Medical University, Dhaka. prevalence and per capita cigarette consumption remain unchanged, there will be close to 1.9 billion uses in 2025 consuming more than 9 trillion cigarette. Consequently, the tobacco related deaths will also increase. ${ }^{3}$

Unlike in developed countries where cigarette smoking is common, both smoking- and chewing-tobacco are prevalent among tobacco users in many developing countries in Africa and Asia. Smoking cigarettes and bidis are common habits among the general male population in Bangladesh. Not only, chewing tobacco like Zarda with betal quid or Gul also common in Bangladesh. ${ }^{4-6}$ Data showed that among the general population of Bangladesh aged 30 years and above tobacco related illnesses accounted for $16 \%$ of the total deaths. ${ }^{7}$ Studies in Bangladesh also reported that smoking positively related with drug use, which is another public health concern. ${ }^{5}$ World Health Organization analyzed the cost of tobacco consumption at the national level is found to be associated with the increased health-care costs, loss of productivity due to illnesses and early deaths and environmental popllution. ${ }^{7}$

Tobacco use prevalence is rising in Bangladesh. It is estimated that more than a third (37\%) of all adults (age 15+) use some form of tobacco and almost half of adult men (49\%) and a quarter of adult women (25\%) currently use tobacco. Among youth (age 13-15) in Dhaka, 6\% currently smoke cigarettes (male 10\%; female 2\%). It was also estimated that more than $10 \%$ of youths in Dhaka currently use tobacco products other than cigarettes (male 13\%; female 7\%). Bidis, cheaper handmade cigarettes, are popular among the poor in Bangladesh and account for $75 \%$ by volume of the cigarettes sold ${ }^{8}$.

This paper analyzes individual tobacco consumption behavior by using data from a purposively selected urban area of Bangladesh. The objective is to identify the factors that influence individuals' tobacco use and also correlates of tobacco use in their health knowledge.

\section{Materials and Methods:}

The study was designed with the major objective to determine the proportion of tobacco use among the adult population aged 18 years above in a selected ward of Meherpur Pourashava. Multistage cluster sampling technique was adopted to select the cluster/ward. After selection of cluster, the respondents were selected by using systematic sampling. A sample of 399 adults aged 18 years and above was interviewed face to face using a semi structured interview schedule. The respondents were informed about the purpose of the study and their voluntary participation was sought. Before interviewing, a written informed consent was taken for assuring that the collected data will be kept confidential. Descriptive measurements were used to define the characteristics of the 
respondents who participated in the study. Due to small number of ex-smokers in the study, non-smokers and ex-smokers were grouped together during the analysis and categorized as nonsmokers. For analytic purposes, the smoking and chewing tobacco use was considered as tobacco use. All $p$ values are based on two sided tests and a significance level of $<5 \%$ was designated. Continuous variables are presented as mean (standard deviation), while qualitative variables were depicted with the use of frequencies. Multivariate analysis was done to assess the independent factors influencing the tobacco use. Data were collected, checked and cross-checked (triangulation) before entry into a computer and analyzed with the help of SPSS Windows Software Program (version 16).

\section{Results:}

Socio-demographic characteristics: Table-I depicted the sociodemographic characteristics of the respondents. The mean age of the respondents was 37.6 (SD 13.8) years. About three fifths of the respondents were aged less than 40 years. Half of the respondents were male (50.1\%) with male-female ratio of 1:1. One fourth (26\%) of the respondents had secondary level of education followed by primary (20\%), higher secondary (17\%) and graduate above (14\%). However, one fourth (24\%) of the respondents were illiterate. Majority of the respondents were married (86\%) and Muslims (94\%). More than one third (35\%) were housewives followed by businessmen (17\%) and serviceholders (17\%). The mean family size was 5.1 (SD 1.7) and the highest percentage had family size 4-5 members (48.6\%. The median income of the respondents was Tk. 8000. Three fifths (56.9\%) of the respondents were living in pucca house followed by $32 \%$ in semi pucca house.

Current Tobacco use and its pattern: Data show that $30 \%$ of the respondents were currently using tobacco of any form either in smoking and chewing. The most frequent form of tobacco use was smoking cigarette followed by zarda with betal quid. On an average, 10 times they use tobacco daily. Their mean age at starting tobacco use was 18.8(SD 5.1) years. Peer pressure appeared to be the main influencing factors for tobacco use (40.7\%) followed by imitation (37.3\%). Daily they spent about Tk. 10.0 for tobacco use (Table -II).

\section{Differentials of tobacco use: Bi-variate and Multivariate} analysis: Bi-variate analysis revealed that age, sex, level of education, religion, occupation, housing condition and level of knowledge on health effect of tobacco use had significant association with current tobacco use $(\mathrm{p}<0.05)$. However, no statistically significant association was found between current tobacco use and marital status, family size, monthly family income ( $p>0.05)$. Data show that the tobacco use was found to
Table-I: Socio-demographic characteristics

\begin{tabular}{|c|c|c|c|}
\hline Characteristics & No. & $\%$ & StatisticsMean(SD) \\
\hline \multicolumn{4}{|l|}{ Age in years } \\
\hline$<40$ & 236 & 59.1 & 37.6(13.8) yrs \\
\hline$\geq 40$ & 163 & 40.9 & Range: $18-79$ yrs \\
\hline \multicolumn{4}{|l|}{ Sex } \\
\hline Male & 200 & 50.1 & \\
\hline Female & 199 & 49.9 & \\
\hline \multicolumn{4}{|l|}{ Level of education } \\
\hline Illiterate & 94 & 23.6 & \\
\hline Primary & 79 & 19.8 & \\
\hline Secondary & 102 & 25.6 & \\
\hline Higher secondary & 67 & 16.8 & \\
\hline Graduate and above & 57 & 14.3 & \\
\hline \multicolumn{4}{|l|}{ Marital status } \\
\hline Unmarried & 57 & 14.3 & \\
\hline Married & 342 & 85.7 & \\
\hline \multicolumn{4}{|l|}{ Religion } \\
\hline Muslim & 373 & 93.5 & \\
\hline Non Muslim & 26 & 6.5 & \\
\hline \multicolumn{4}{|l|}{ Occupation } \\
\hline Unemployed & 40 & 10.0 & \\
\hline Labourer & 54 & 13.5 & \\
\hline Business & 66 & 16.5 & \\
\hline Service & 66 & 16.5 & \\
\hline Housewife & 141 & 35.3 & \\
\hline Student & 32 & 8.0 & \\
\hline \multicolumn{4}{|l|}{ Family size } \\
\hline $1-3$ & 56 & 14.0 & 5.1(1.7) \\
\hline $4-5$ & 194 & 48.6 & Range: 1-11 \\
\hline $6-7$ & 106 & 26.6 & \\
\hline$\geq 7$ & 43 & 10.8 & \\
\hline \multicolumn{4}{|c|}{ Monthly Family Income (Tk.) } \\
\hline$£ 8000$ & 221 & 55.4 & Median=Tk.8000 \\
\hline$>8000$ & 178 & 44.6 & Range: Tk. $1000-45,000$ \\
\hline \multicolumn{4}{|l|}{ Housing condition } \\
\hline Katcha & 46 & 11.5 & \\
\hline Semi-pucca & 126 & 31.6 & \\
\hline Pucca & 227 & 56.9 & \\
\hline
\end{tabular}


Table-II : Tobacco use, its pattern and factors influencing tobacco use

\begin{tabular}{|c|c|c|c|}
\hline Characteristics & No. & $\%$ & $\begin{array}{c}\text { Statistics } \\
\text { Mean(SD) }\end{array}$ \\
\hline \multicolumn{4}{|l|}{ Tobacco use } \\
\hline Yes & 118 & 29.6 & \\
\hline No & 281 & 70.4 & \\
\hline \multicolumn{4}{|c|}{ Pattern of smoking $(n=118)$} \\
\hline Cigarette & 80 & 67.8 & \\
\hline Bidi & 4 & 3.4 & \\
\hline Zarda & 21 & 17.8 & \\
\hline Gul & 5 & 4.2 & \\
\hline Tobacco leaf & 4 & 3.4 & \\
\hline Smoking and chew & $\mathrm{CCO}$ & 4 & 3.4 \\
\hline \multicolumn{4}{|c|}{ Frequency of tobacco use $(n=118)$} \\
\hline $1-5$ & 26 & 22.0 & $\mathrm{Md}=10.0$ times \\
\hline $6-10$ & 51 & 43.2 & Range: 2-40 times \\
\hline $11-15$ & 20 & 16.9 & \\
\hline e”16 & 21 & 17.8 & \\
\hline \multicolumn{4}{|c|}{ Age at starting smoking $(\mathrm{n}=118)$} \\
\hline$<20$ & 64 & & 18.8(5.1) yrs \\
\hline e”20 & 54 & & Range: $10-49$ yrs \\
\hline \multicolumn{4}{|c|}{ Factor influencing smoking( $\mathrm{n}=118)$} \\
\hline Peer pressure & 48 & 40.7 & \\
\hline Imitation & 44 & 37.3 & \\
\hline No reasons & 17 & 14.4 & \\
\hline To relieve tension & 9 & 7.6 & \\
\hline \multicolumn{4}{|c|}{ Daily cost for tobacco use(n=117) } \\
\hline$<20$ & 68 & 58.1 & $\mathrm{Md}=\mathrm{Tk} .10 .0$ \\
\hline$\geq 20$ & 49 & 41.9 & Range: Tk. 1-100 \\
\hline
\end{tabular}

be high among the respondents aged 40 years and above, who are male, illiterate, Muslim, labourer and businessmen, living in katcha house and poor level of knowledge (Table-III). Multivariate logistic regression analysis was carried out to assess the independent factors influencing tobacco use. Accordingly, due to small sample size, all the ex-tobacco users (either smoking or chewing) were categorized as non tobacco users. The tobacco use was dichotomized into yes and no and considered as dependent variable. Seven variables, out of ten variables fitted in bi-variate analysis showed significant association with current tobacco use which were entered into logistic regression model. Analysis revealed that illiterate respondents were 3.3 times tobacco users than their educated counterparts. It was also higher among the Muslims (OR=4.979; $95 \% \mathrm{CI}=1.255-19.754)$. It was also found higher among the labouerer ( $\mathrm{OR}=8.541$; 95\% $\mathrm{CI}=2.422-30.120)$ and businessmen (OR=7.727, 95\% CI=2.501-23.875). However, no statistically significant association was found between current tobacco use and age, sex, housing condition and knowledge on tobacco use ( $\mathrm{p}>0.05)$ (Table-IV).

Table-III : Relationship between tobacco use and selected variables

\begin{tabular}{|c|c|c|c|c|}
\hline Variables & $\mathrm{N}$ & $\begin{array}{c}\text { Tobacco use } \\
\text { Yes (\%) }\end{array}$ & $\begin{array}{l}\text { p value } \\
\text { No(\%) }\end{array}$ & \\
\hline \multicolumn{5}{|l|}{ Age in years } \\
\hline$<40$ & 236 & 22.5 & 77.5 & 0.001 \\
\hline$\geq 40$ & 133 & 39.9 & 60.1 & \\
\hline \multicolumn{5}{|l|}{ Sex } \\
\hline Male & 200 & 46.5 & 53.5 & 0.001 \\
\hline Female & 199 & 12.6 & 87.4 & \\
\hline \multicolumn{5}{|l|}{ Level of education } \\
\hline Illiterate & 94 & 53.2 & 46.8 & 0.001 \\
\hline Primary & 79 & 31.6 & 68.4 & \\
\hline Secondary & 102 & 21.6 & 78.4 & \\
\hline Higher secondary & 67 & 14.9 & 85.1 & \\
\hline Graduate and above & 57 & 19.3 & 80.7 & \\
\hline \multicolumn{5}{|l|}{ Marital status } \\
\hline Unmarried & 57 & 19.3 & 80.7 & 0.066 \\
\hline Married & 342 & 31.3 & 68.7 & \\
\hline \multicolumn{5}{|l|}{ Religion } \\
\hline Muslim & 373 & 30.8 & 69.2 & 0.037 \\
\hline Non Muslim & 26 & 11.5 & 88.5 & \\
\hline \multicolumn{5}{|l|}{ Occupation } \\
\hline Unemployed & 40 & 27.5 & 72.5 & 0.001 \\
\hline Labourer & 54 & 70.4 & 29.6 & \\
\hline Business & 66 & 57.6 & 42.4 & \\
\hline Service & 66 & 21.2 & 78.8 & \\
\hline Housewife & 141 & 9.9 & 90.1 & \\
\hline Student & 32 & 9.4 & 90.6 & \\
\hline \multicolumn{5}{|l|}{ Family size } \\
\hline $1-3$ & 56 & 25.0 & 75.0 & 0.065 \\
\hline $4-5$ & 194 & 26.8 & 73.2 & \\
\hline $6-7$ & 106 & 30.2 & 69.8 & \\
\hline$\geq 7$ & 43 & 46.5 & 53.5 & \\
\hline \multicolumn{5}{|c|}{ Monthly Family Income (Tk.) } \\
\hline$£ 8000$ & 221 & 30.8 & 69.2 & 0.560 \\
\hline$>8000$ & 178 & 28.1 & 71.9 & \\
\hline \multicolumn{5}{|l|}{ Housing condition } \\
\hline Katcha & 46 & 54.3 & 45.7 & 0.001 \\
\hline Semi-pucca & 126 & 32.5 & 67.5 & \\
\hline Pucca & 227 & 22.9 & 77.1 & \\
\hline \multicolumn{5}{|l|}{ Level of knowledge } \\
\hline Poor & 159 & 34.6 & 65.4 & 0.002 \\
\hline Fair & 80 & 38.8 & 61.3 & \\
\hline Good & 160 & 20.0 & 80.0 & \\
\hline
\end{tabular}


Table-IV : Correlates of tobacco use with selected socio-demographic variables:

\begin{tabular}{|c|c|c|c|c|}
\hline \multicolumn{5}{|l|}{ Multivariate analysis } \\
\hline Characteristics & $\mathrm{b}$ & $\mathrm{p}$ value & Odds ratio & 95.0\% C.I \\
\hline \multicolumn{5}{|l|}{ Age in years } \\
\hline$<40$ (RC) & - & - & - & - \\
\hline$\geq 40$ & 0.539 & 0.078 & 1.714 & $0.941-3.121$ \\
\hline \multicolumn{5}{|l|}{ Sex } \\
\hline Male & 0.599 & 0.211 & 1.821 & $0.712-4.658$ \\
\hline Female(RC) & - & - & - & - \\
\hline \multicolumn{5}{|l|}{ Level of education } \\
\hline Illiterate & $1.206^{*}$ & 0.034 & 3.340 & $1.095-10.187$ \\
\hline Primary & 0.376 & 0.483 & 1.457 & $0.509-4.168$ \\
\hline Secondary & 0.494 & 0.338 & 1.639 & 0.596-4.506 \\
\hline Higher secondary & 0.155 & 0.770 & 1.168 & 0.412-3.305 \\
\hline Graduate and above (RC) & - & - & - & - \\
\hline \multicolumn{5}{|l|}{ Religion } \\
\hline Muslim & $1.605^{*}$ & 0.022 & 4.979 & $1.255-19.754$ \\
\hline Non Muslim(RC) & - & - & - & - \\
\hline \multicolumn{5}{|l|}{ Occupation } \\
\hline Unemployed & 0.110 & 0.841 & 1.117 & 0.379-3.294 \\
\hline Labourer & $2.145^{* * *}$ & 0.001 & 8.541 & $2.422-30.120$ \\
\hline Business & $2.045^{* * *}$ & 0.001 & 7.727 & $2.501-23.875$ \\
\hline Service & 1.126 & 0.056 & 3.083 & 0.970-9.794 \\
\hline Housewife (RC) & - & - & - & - \\
\hline \multicolumn{5}{|l|}{ Housing condition } \\
\hline Katcha & 0.658 & 0.169 & 1.931 & $0.756-4.933$ \\
\hline Semi-pucca & 0.136 & 0.676 & 1.146 & $0.605-2.168$ \\
\hline Pucca (RC) & - & - & - & - \\
\hline \multicolumn{5}{|c|}{ Knowledge on tobacco related disease } \\
\hline Poor & 0.485 & 0.138 & 1.624 & $0.855-3.084$ \\
\hline Fair & 0.749 & 0.052 & 2.114 & $0.993-4.500$ \\
\hline \multicolumn{5}{|l|}{ Good (RC) } \\
\hline Model Chi Square & 135.72 & & & \\
\hline df & 15 & & & \\
\hline $\mathrm{N}$ & 339 & & & \\
\hline Constant & -5.047 & & & \\
\hline
\end{tabular}

$\mathrm{RC}=$ Reference category ${ }^{*} \mathrm{p}<0.05 ;{ }^{* *} \mathrm{p}<0.01 ;{ }^{* * *} \mathrm{p}<0.001$

Variables not included in the regression model are: marital status, family size and monthly family income i.e. these are not statistically significant in bi-variate analysis.

\section{Discussion:}

This paper has investigated the socio-economic determinants of the probability of tobacco chewing, smoking and knowledge of the health risks of tobacco use. The overall tobacco use prevalence was 30\%. A nationwide survey by Hossain et al.,(1996) ${ }^{9}$ found that it was $25.2 \%$ of the population aged 15 years and above. The proportion of tobacco use was found to be high among male (47\%) than female(13\%). The prevalence of female tobacco was much lower than Chowdhury et al.,(2007). ${ }^{10}$ They reported that it was $24 \%$. However, the tobacco use status might be underreported in the present study. In fact, smoking by women is not socially accepted in Bangladesh, but the chewing tobacco use increased with age especially 30 years and above after marriage. Smoking or 
chewing tobacco use among the young people is discouraged. However, smoking is not uncommon among the friend circles. Similar pattern of gender differential of tobacco use was found in Muslim countries like Saudi Arabia. ${ }^{11}$ But the female smoking is different in western countries, where female smoking was more common. ${ }^{12,13}$ On the contrary, same restrictions do not apply to the consumption of chewing tobacco with paan. In fact the female in Bangladesh are more habituated with chewing tobacco in older age group.

Education appeared to be an important predictor of tobacco use in the present study and it was 3.3 times higher among the illiterate compared to the educated respondents. Jarallah has reported that smoking is $20 \%$ increase in the odds for individuals in the lower educational category of the population. ${ }^{11}$ This might be fact that illiterate people consume tobacco due to their poor knowledge in health consequence of tobacco use. Though multivariate analysis did not identify the important predictor of tobacco use, but bi-variate analysis revealed that poor knowledge tobacco related issues appeared to be important factors for tobacco use. Similar findings were reported by Gurmu and Yunus (2008). ${ }^{14}$ There is strong evidence that the effects vary across different socio-economic groups and by types of tobacco use. Limitation of the study indicated the cross sectional nature of our data and lack of information on key explanatory variables (e.g., prices) precludes detailed analysis of participation, consumption along with the effectiveness of tobacco control policies.

The World Health Organization (WHO) has provided countries with guidelines for national tobacco control programmes. ${ }^{15}$ These guidelines include health promotion activities, media campaign, encouragement of smoking cessation, legislative measures, fiscal measures such as tobacco taxation, protective measures against involuntary exposure to secondhand smoke and counter activities of tobacco industries. The present study though not to be generalized, but analysis revealed that poor level of knowledge, illiteracy appeared to be most important factors for tobacco use. Future research directions might broaden the analysis for developing tobacco economy and health consequence that need to be consideration in identification of differential risks of tobacco use and policy formulation.

\section{References:}

1. Esson KM and Leeder SR Goals and Tobacco Control: An opportunity for Global partnership. World Health Organization (WHO), 2004.

2. World Health Organization: Combing the tobacco epidemic: In world health report. Geneva: World Health Organization; 1999.
3. Guindon GE and Boisclair D. Past, current and future trends in tobacco use. HNP Discussion paper. Economics Tobacco Control Paper 6. Tobacco Free Initiative. World Health Organization. 2003

4. Choudhury K, Hanifi SMA, Mahmood SS, Bhuiya A: Sociodemographic characteristics of tobacco consumers in a rural area of Bangladesh. J Health Popul Nutr 2007, 25:456-464.

5. Khan MMH, Khandoker A, Kabir MA, Kabir M, Mori M: Tobacco consumption and its association with illicit drug use among men in Bangladesh. Addiction 2006, 101:11781186.

6. Rahman M, Chowdhury AS, Fukui T, Hira K, Shimbo T: Association of thromboangiitis obliterans with cigarette and bidi smoking in Bangladesh: a case-control study. Int J Epidemiol 2000, 29:266-270.

7. World Health Organization: Impact of tobacco-related illnesses in Bangladesh. Dhaka: World Health Organization; 2005.

8. Tobacco Burden facts 2009), March 2009. bangladesh. Ratified the Frmework Convention on Tobacco Control on June 14, 2004. On line Available: www.tobaccofreecenter.org. Accessed on 08 May 2009.

9. Hossain MS, Amin MR, Rahman MH. Prevalence of smoking in Bangladesh. Dhaka: Bangladesh Bureau of Statistics, 1996. $12 \mathrm{p}$.

10. Choudhury K, Hanifi SMA, Shehrin Shaila Mahmood SS, and Bhuiya A

Sociodemographic Characteristics of Tobacco Consumers in a Rural Area of Bangladesh. J Health Popul Nutr 2007 Dec;25(4):456-464

11. Jarallah JS, Al-Rubeaan KA, Al-Nuaim AAA, Al-Ruhaily AA, Kalantan KA. Prevalence and determinants of smoking in three regions of Saudi Arabia. Tobacco Control 1999;8:53-5653

12. Lopez AD, Collishaw NE, Piha T. A descriptive model of the cigarette epidemic in developed countries. TobaccoControl 1994;3:242-7.

13. Fiore MC, Novotny TE, Pierce JP, et al. Trends in cigarette smoking in the United States: the changing influence of gender and race. JAMA 1989;261:49-55.

14. Gurmu, S and Yunus M. Tobacco Chewing, Smoking and Health Knowledge: Evidence from Bangladesh. Economics Bulletin,9;10:1-9

15. World Health Organisation. Evaluating tobacco control activities: experiences and guideline principles. WHO, Geneva, 1996. 